\title{
Nonexcisional, Minimally Invasive Rejuvenation of the Neck Using Radiofrequency Tissue Tightening (FaceTite $^{\mathrm{TM}}$ )
}

Jin Seok Kang ${ }^{1}$, Seong Eun Cho ${ }^{1}$, Seung Min Nam², Eun Soo Park ${ }^{2}$

${ }^{1}$ Department of Plastic and

Reconstructive Surgery, Soonchunhyang University College of Medicine, Seoul;

${ }^{2}$ Department of Plastic and

Reconstructive Surgery, Soonchunhyang University College of Medicine, Bucheon, Korea

This work was supported by the Soonchunhyang University Research Fund.

No potential conflict of interest relevant to this article was reported.
Background Noninvasive radiofrequency $(\mathrm{RF})$ and lasers have been used for skin tightening and body contouring since the 1990s. The safety, efficacy, and patient satisfaction with the procedure using a novel RF device (BodyTite ${ }^{T M}$; Invasix Ltd, Yokneam llit, Israel) were evaluated.

Methods We retrospectively included 13 patients who were treated with the Body$\mathrm{Tite}^{\mathrm{TM}}$ to rejuvenate neck skin from May 2012 to May 2014. The power of the device was set between 10 and $15 \mathrm{~W}$. The target temperature was set at $38^{\circ} \mathrm{C}$. Three independent evaluators were asked to grade baseline and 6- to 12-month follow-up photographs using a comprehensive quantitative 4-point laxity grading scale. All patients were asked to rate their satisfaction with the aesthetic outcome and quality of life after treatment. Results Grading results of baseline and follow-up photographs of patients were statistically significant with an average grade improvement of 1.01 points on the 4 point scale. Using a patient satisfaction scale, patients were also significantly more satisfied (poor, 0\%; fair, 15\%; good, 46\%; and excellent, 39\%). There were transient complications, such as minimal erythema, mild edema, and focal hardness, which resolved spontaneously within 1 week. There were no significant adverse effects or complications. Conclusions The BodyTite ${ }^{\mathrm{TM}}$ is a minimally invasive, RF treatment that was demonstrated to improve skin laxity without significant adverse effects or complications. The BodyTite $^{\mathrm{TM}}$ provides a nonsurgical option for the safe and effective rejuvenation of neck skin under local anesthesia.

Keywords Aging face, Radiofrequency, Rejuvenation

\section{INTRODUCTION}

There are nonsurgical and nonexcisional alternatives for lower face and neck lifts, including traditional liposuction, laser-assisted liposuction (LAL), skin surface skin tightening technologies, and minimally invasive skin tightening (MIST). Although traditional tume-

Received: Jul 2, 2015 Revised: Aug 11, 2015 Accepted: Aug 13, 2015 Correspondence: Eun Soo Park Department of Plastic and Reconstructive Surgery, Soonchunhyang Univsersity Bucheon Hospital, 170 Jomaru-ro, Wonmi-gu, Bucheon 14584, Korea. E-mail: peunsoo@schmc.ac.kr

Copyright () 2015 The Korean Society for Aesthetic Plastic Surgery.

This is an Open Access article distributed under the terms of the Creative Commons Attribution Non-Commercial License (http://creativecommons.org/licenses/by-nc/3.0/) which permits unrestricted non-commercial use, distribution, and reproduction in any medium, provided the original work is properly cited. $\quad w w w . e-a a p s . o r g$ scent neck liposuction is highly effective at contouring and fat removal, it fails to address the residual skin laxity left behind completely in a number of cases [1-3]. While easily facilitating lipolysis and removal, neck LAL fails to manage residual skin laxity adequately [4].

In contrast to skin surface technologies, the use of needle electrodes or fiber cannula MIST delivers the laser or radiofrequency (RF) energy immediately into the dermis or subdermal tissue, maximizing efficacy in treating lower face and neck laxity $[5,6]$.

Noninvasive RF and lasers have been used for skin tightening and body contouring since the 1990s. An RF device (BodyTite ${ }^{\mathrm{TM}}$; Invasix Ltd, Yokneam Ilit, Israel) was introduced in 2008 to contract skin and soft tissue, and treat subcutaneous adipose regions. The RF energy elicits its effects on the fibroseptal network and triggers skin tightening and soft tissue contraction $[7,8]$. RF energy in- 
duces thermal stimulation to cause skin surface contraction of up to $45 \%$ [9].

The purpose of our study was to evaluate the safety, efficacy, and patient satisfaction with the neck tightening procedure using a novel RF device (BodyTite ${ }^{\mathrm{TM}}$ ) and using FaceTite ${ }^{\mathrm{TM}}$ as the hand piece.

\section{METHODS}

In this study, we retrospectively included 13 patients who were treated with the RF device (BodyTite ${ }^{\mathrm{TM}}$ ) to rejuvenate neck skin under local anesthesia from May 2012 to May 2014. All participants provided verbal and written consent before enrollment. Patient consent for photography was also taken before treatment. Pre- and post-treatment photographs were also obtained. Blinded grading was performed by three independent evaluators, including plastic surgeons and nurses, using a quantitative 4-point grading scale to assess changes in skin laxity [10] (Table 1). All patients were asked to assess their satisfaction with the aesthetic outcome and quality of life after treatment using a 4-point subjective scale of excellent, good, fair, and poor.

Inclusion criteria were good health and mild to severe laxity (minimum baseline laxity, grade 2). Exclusion criteria consisted of any injection history such as silicone, fat, collagen, or a synthetic material; bleeding or coagulation disorder; history of a hypertrophic scar or keloid; and isotretinoin treatment in the past 12 months. Other exclusion criteria included a compromised immune system, impaired wound healing, collagen vascular disease, an implantable electronic device (e.g., pacemaker), or active infection. Participants were required to be available for post-treatment follow-up evaluations.

The RF treatments were performed by the corresponding author (ESP). The FaceTite ${ }^{\mathrm{TM}}$ was used as the hand piece for treatment (Fig. 1). Before treatment, the patient's skin was cleansed with beta-

Table 1. Skin laxity grading scale

\begin{tabular}{|c|c|c|}
\hline Grade & $\begin{array}{l}\text { Descriptive } \\
\text { parameter }\end{array}$ & Laxity \\
\hline 0 & None & None \\
\hline 1 & Mild & Localized to $\mathrm{nl}$ folds \\
\hline 1.5 & Mild & Localized, $\mathrm{nl}$ and early $\mathrm{ml}$ folds \\
\hline 2 & Moderate & Localized, $\mathrm{nl} / \mathrm{ml}$ folds, early jowls, early sm \\
\hline 2.5 & Moderate & Localized, prominent $\mathrm{nl} / \mathrm{ml}$ folds, jowls and sm \\
\hline 3 & Advanced & $\begin{array}{l}\text { Prominent } \mathrm{nl} / \mathrm{ml} \text { folds, jowls and sm, early neck } \\
\text { strands }\end{array}$ \\
\hline 3.5 & Advanced & $\begin{array}{l}\text { Deep } \mathrm{nl} / \mathrm{ml} \text { folds, prominent jowls and sm, promi- } \\
\text { nent neck strands }\end{array}$ \\
\hline 4 & Severe & $\begin{array}{l}\text { Marked } \mathrm{nl} / \mathrm{ml} \text { folds, jowls and sm, neck redundancy } \\
\text { and strands }\end{array}$ \\
\hline
\end{tabular}

Adapted from Alexiades-Armenakas.

$\mathrm{nl}$, nasolabial folds; $\mathrm{ml}$, melolabial folds; sm, submental/submandibular.

dine (Purdue Pharma, Stamford, Connecticut). Patients received a local injection of 1:100,000 epinephrine mixed with $0.5 \%$ lidocaine at the incision site. An additional local anesthetic (mean quantity, $100 \mathrm{~mL}$ tumescent solution) was used in the submental and lateral neck regions. Settings were 10 and $15 \mathrm{~W}$, with an endpoint epidermal skin temperature of $38^{\circ} \mathrm{C}$. Postoperatively, the patient's skin was cleansed with normal saline, and Vaseline gauze was applied. Patients were allowed to return to normal activities immediately, were prohibited from wearing makeup for 24 hours, and were asked to avoid sun exposure for 14 days. Patients were followed up 12 months after treatment. Patients were required to report any discomfort, adverse effects, and complications during or following



NeckTite

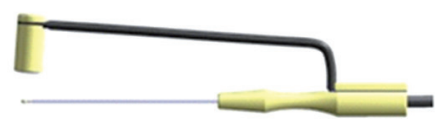

FaceTite $^{T M}$

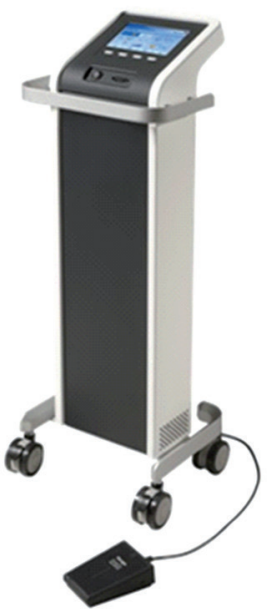

Fig. 1. Radiofrequency tissue tightening device and hand pieces.

Grade 2.5

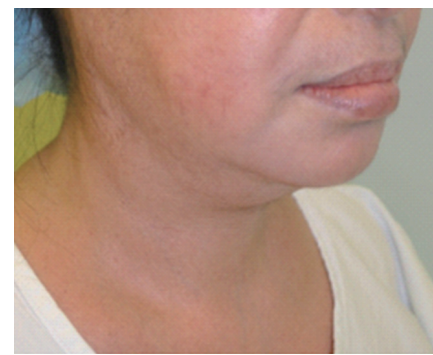

Grade 3.5

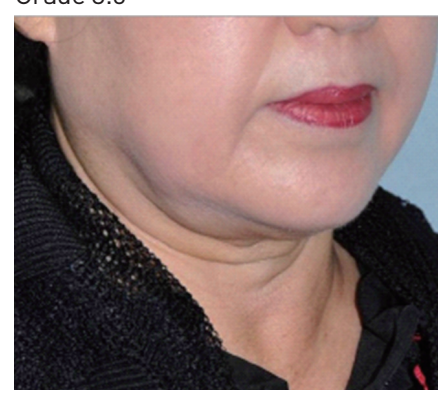

Fig. 2. Examples of skin laxity scale adapted from Alexiades-Armenakas.

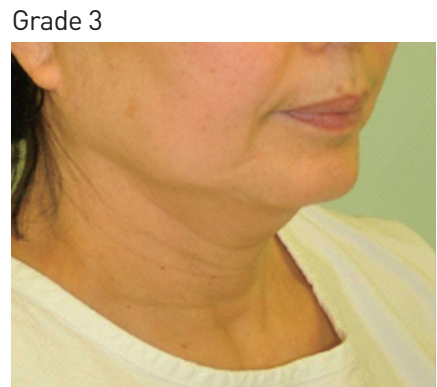

Grade 4




treatment. At follow-up visits, patients were asked to rate their overall satisfaction.

Standardized photographs were taken for the patient at baseline on the day of treatment and during the follow-up visits. The photographs were cropped and randomized equally. Three independent blinded evaluators graded the images using the Quantitative Comprehensive Grading Scale for facial and neck laxity [10] (Table 1, Fig. 2). Blinded evaluators categorized the patient's laxity grade based on the specific findings (e.g., neck strands). Mean baseline and follow-up grades with standard deviations were calculated for each patient. Pre- and post-treatment grades were compared using the Wilcoxon signed-rank test by SPSS version 20.0 (SPSS Inc., Chicago, IL, USA). Differences were considered statistically significant when $P$ was less than 0.05 .

\section{RESULTS}

The mean baseline and follow-up laxity grades based on the 4-point laxity grading scale were 3.04 and 2.03, respectively (Table 2). Grading results of baseline and follow-up photographs of patients showed statistically significant improvement in neck skin laxity with an average grade improvement of 1.01 points on the 4-point laxity grading scale $(\mathrm{P}<0.05)$. Clinical outcomes of patients after $\mathrm{RF}$ treatment are shown in Fig. 3 to 5. The results of the grading evaluation and statistical analysis for the patient are shown in Table 2. Patient satisfaction with RF treatment was high: 39\% reported excellent satisfaction; $46 \%$, good; $15 \%$, fair; and $0 \%$, poor.

There were transient complications, such as minimal erythema,

Table 2. Patient characteristics pre- \& post-treatment

\begin{tabular}{|c|c|c|c|c|c|}
\hline \multirow[b]{2}{*}{ No. } & \multirow[b]{2}{*}{ Sex/age } & \multicolumn{3}{|c|}{ Laxity grade } & \multirow{2}{*}{$\begin{array}{c}\text { Patient } \\
\text { satisfaction } \\
\text { scale }\end{array}$} \\
\hline & & $\begin{array}{l}\text { Baseline } \\
\text { laxity }\end{array}$ & $\begin{array}{l}\text { Follow-up } \\
\text { laxity }\end{array}$ & $\begin{array}{l}\text { Laxity } \\
\text { change }\end{array}$ & \\
\hline 1 & $\mathrm{~F} / 47$ & 2.33 & 1.5 & 0.83 & Fair \\
\hline 2 & $F / 56$ & 2.67 & 1.67 & 1 & Good \\
\hline 3 & $F / 53$ & 2.83 & 1.67 & 1.17 & Excellent \\
\hline 4 & $F / 56$ & 2.67 & 1.83 & 0.83 & Fair \\
\hline 5 & $M / 69$ & 3.33 & 1.83 & 1.5 & Excellent \\
\hline 6 & $\mathrm{~F} / 65$ & 3.17 & 2.17 & 1 & Good \\
\hline 7 & $F / 67$ & 3.17 & 2.17 & 1 & Excellent \\
\hline 8 & $F / 72$ & 3.83 & 2.67 & 1.17 & Fair \\
\hline 9 & $\mathrm{~F} / 47$ & 3.33 & 2.17 & 1.17 & Excellent \\
\hline 10 & $F / 56$ & 2.83 & 1.83 & 1 & Excellent \\
\hline 11 & $F / 62$ & 3.83 & 2.83 & 1 & Excellent \\
\hline 12 & $F / 52$ & 3.17 & 2.33 & 0.83 & Good \\
\hline 13 & $\mathrm{~F} / 43$ & 2.33 & 1.67 & 0.67 & Fair \\
\hline Mean & & 3.04 (SD 0.49) & 2.03 (SD 0.41) & 1.01 (SD 0.21) & \\
\hline
\end{tabular}

F, female; M, male; SD, standard deviation.
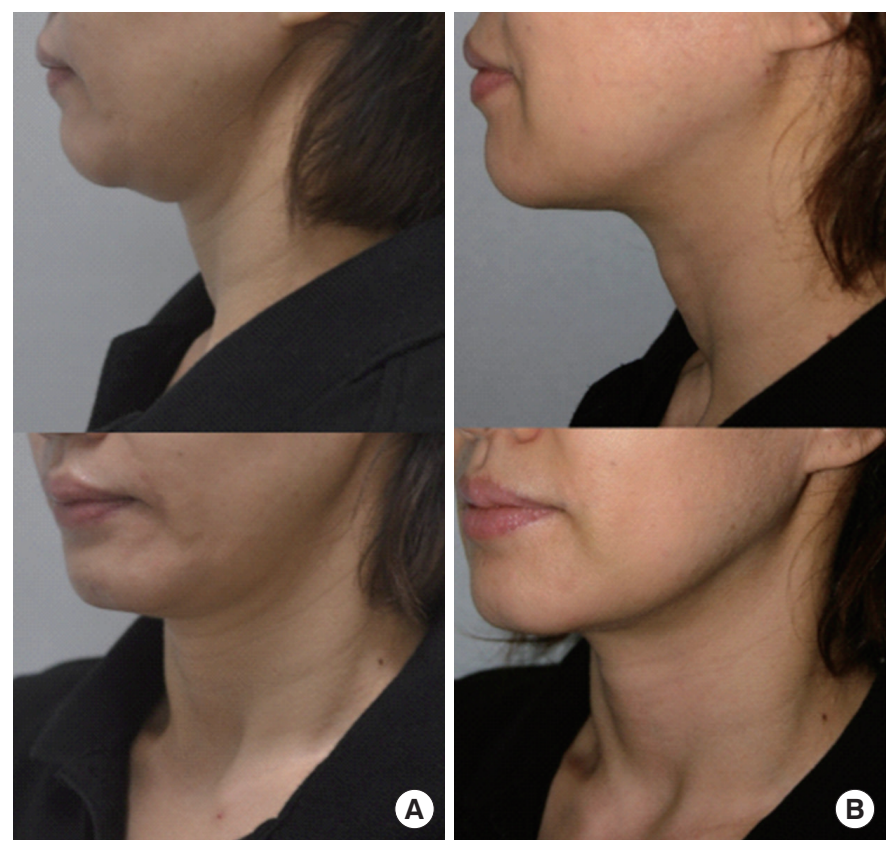

Fig. 3. A 47-year-old female prior to treatment $(A)$ and 6 months after treatment (B). These photographs show nearly complete resolution of the redundant surrounding submental skin and improvement of the neck strands.
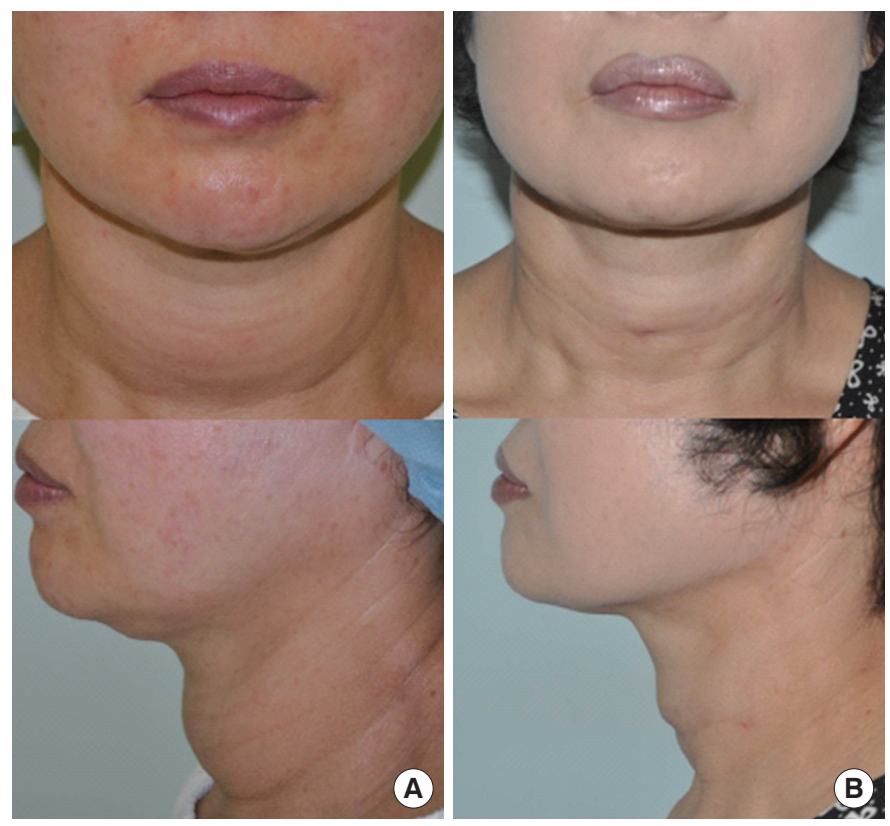

Fig. 4. A 53-year-old female prior to treatment (A) and 8 months after treatment (B). She had a granuloma on the anterior neck caused by a previous filler injection. We excised the granuloma and rejuvenated the neck skin using the radiofrequency device. These photographs show improvement of the redundant surrounding submental \& neck skin, and improvement of the neck strands. 

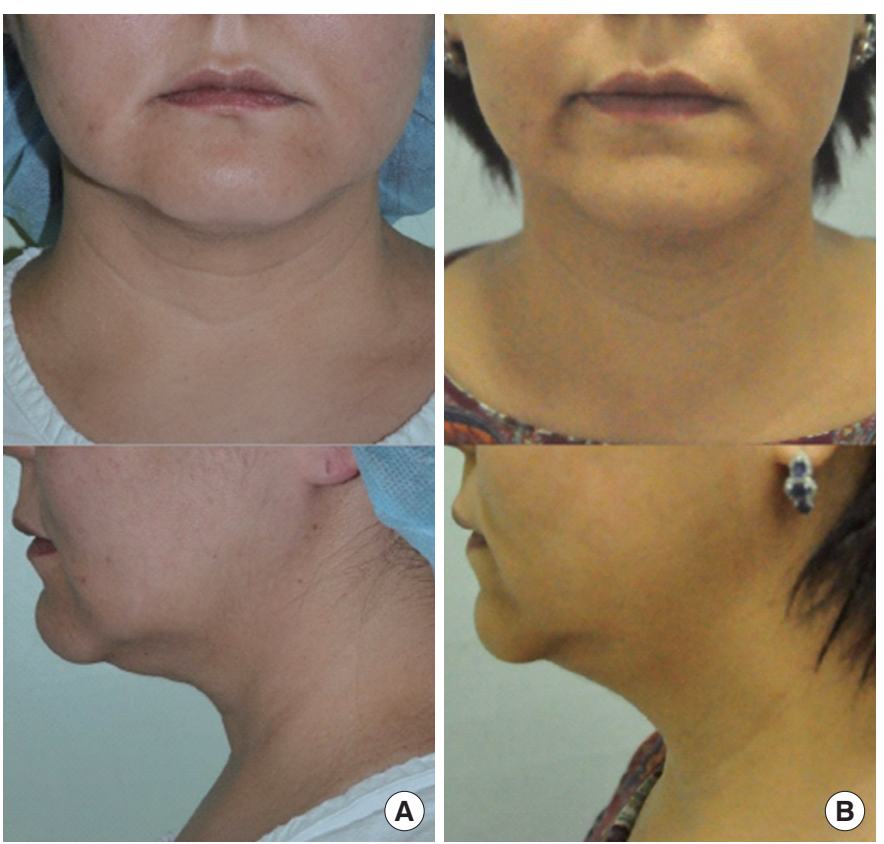

Fig. 5. A 43-year-old female prior to treatment (A) and 12 months after treatment (B). These photographs show nearly complete resolution of the redundant surrounding submental skin and improvement of the neck strands.

mild edema, and focal hardness, which resolved spontaneously within 1 week. Subjects who took pain relievers preemptively reported no pain during the postoperative period. There were no surface irregularities, numbness, or difficulty speaking, and there were no significant adverse effects or complications. Patients could return to their normal activity immediately after treatment.

\section{DISCUSSION}

In previous studies using various laser- and light-based devices, dermal temperatures greater than $55^{\circ} \mathrm{C}$ are required to induce collagen denaturation; this denaturation is followed by neocollagenesis during a 6- to 12-month period [11]. The disadvantage of prior modalities is that they rely on skin surface infrared temperature measurements. The advantage of the current RF device is that, using real-time temperature feedback, it allows a specific target temperature at the dermal treatment site.

Furthermore, the time-at-temperature can produce adequate thermal denaturation. Dermal thermal injury is followed by progressive neocollagenesis and correlates with progressive tissue tightening [11]. The BodyTite ${ }^{\mathrm{TM}}$ system's mechanism protects from thermal injury. During our study, that temperature was set at $38^{\circ} \mathrm{C}$ to avoid injury to the skin. Other studies used cut-off settings of skin temperature between 40 and $42^{\circ} \mathrm{C}[12,13]$.

The FaceTite ${ }^{\mathrm{TM}}$ is composed of a silicone-coated, solid RF-emitting probe with a plastic tip to avoid subdermal "end hit" thermal injuries. The FaceTite ${ }^{\mathrm{TM}}$ has internal and external electrodes. The RF energy is delivered from the internal to the external electrode, coagulating subcutaneous fat in close proximity to the electrode in the superficial subdermal space while gradually heating the papillary dermis, as the electrodes glide along the epidermal surface. The thermal denaturation of the reticular dermis, allows the papillary dermis to be preserved. The external electrode has special sensors that deliver information to the console to which the FaceTite ${ }^{\mathrm{TM}}$ is connected, which responds by turning the RF energy on or off. Consequentially, rising dermal temperatures rapidly turn off the RF energy when the conditions approach dangerous thermal levels. The temperature is monitored 10 times per millisecond. The safe, prolonged exposure of thermal energy tightens the subdermal tissue and optimizes soft tissue contraction and tightening. It is believed that thermal injury to the dermis triggers dermal remodeling and neocollagenesis [14].

Previous studies quantitatively evaluated nonsurgical skin tightening techniques using the same quantitative 4-point grading scale as our study; however, the current device showed a much higher efficacy in treating skin laxity. In prior studies, a 0.075 to 0.236 mean laxity grade improvement per treatment using RF or infrared laser or light devices was reported [15-18]. The current device showed a mean grade improvement of 1.01, significantly higher than all prior studies.

In this study, there were no significant adverse effects or complications. Patient satisfaction was high. As a nonsurgical, minimally invasive treatment under local anesthesia, the current device offer a reasonable option for patients who are afraid of surgical procedures or surgical scars. In addition, patients increasingly want to resume their normal activities quickly after the procedure and also worry about long-lasting or significant side effects.

With regard to long-term effects, we monitored patient responses to RF treatment up to 2 years in our outpatient clinic. There was no significant worsening of skin laxity during the follow-up period. In addition, no patients considered a revision procedure. During the 6- to 12-month follow-up period, collagen denaturation and neocollagenesis were induced [11]. If necessary, a revision procedure can be considered 1 year after the initial treatment.

The limitations of this study include a lack of comparison with a control group treated by other modalities. A blinded and randomized comparative study could help identify the effects of RF treatment more precisely. Second, the number of patients is relatively small. A large population study could help evaluate the results more accurately. Lastly, the term of the study is relatively short. Longerterm follow-up visits are needed to evaluate the course of the results.

The BodyTite ${ }^{\mathrm{TM}}$ is a minimally invasive RF treatment that improved skin laxity without significant adverse effects or complications. The BodyTite ${ }^{\mathrm{TM}}$ provides a nonsurgical option for the safe and effective for treatment of neck skin laxity under local anesthesia. 


\section{PATIENT CONSENT}

Patients provided written consent for the use of their images.

\section{REFERENCES}

1. Langdon RC. Liposuction of neck and jowls: five-incision method combining machine-assisted and syringe aspiration. Dermatol Surg 2000;26:388-91.

2. Gryskiewicz JM. Submental suction-assisted lipectomy without platysmaplasty: pushing the (skin) envelope to avoid a face lift for unsuitable candidates. Plast Reconstr Surg 2003;112:1393-405; discussion 406-7.

3. Alegría Perén P, Barba Gómez J, Guerrero-Santos J. Total corporal contouring with megaliposuction (120 consecutive cases). Aesthetic Plast Surg 1999;23:93-100.

4. Noodleman FR, Harris DR. The laser-assisted neck lift: modifications in technique and postoperative care to improve results. Dermatol Surg 2002;28:453-8.

5. Hantash BM, Renton B, Berkowitz RL, et al. Pilot clinical study of a novel minimally invasive bipolar microneedle radiofrequency device. Lasers Surg Med 2009;41:87-95.

6. Alexiades-Armenakas M, Rosenberg D, Renton B, et al. Blinded, randomized, quantitative grading comparison of minimally invasive, fractional radiofrequency and surgical face-lift to treat skin laxity. Arch Dermatol 2010;146:396-405.

7. Paul M, Blugerman G, Kreindel M, et al. Three-dimensional radiofrequency tissue tightening: a proposed mechanism and applications for body contouring. Aesthetic Plast Surg 2011;35:87-95.

8. Hurwitz D, Smith D. Treatment of overweight patients by radiofrequency-assisted liposuction (RFAL) for aesthetic reshaping and skin tightening. Aesthetic Plast Surg 2012;36:62-71.
9. Blugerman G, Schavelzon D, Paul MD. A safety and feasibility study of a novel radiofrequency-assisted liposuction technique. Plast Reconstr Surg 2010;125:998-1006.

10. Alexiades-Armenakas M. A quantitative and comprehensive grading scale for rhytides, laxity, and photoaging. J Drugs Dermatol 2006;5: 808-9.

11. Alexiades-Armenakas MR, Dover JS, Arndt KA. The spectrum of laser skin resurfacing: nonablative, fractional, and ablative laser resurfacing. J Am Acad Dermatol 2008;58:719-37.

12. Ahn DH, Mulholland RS, Duncan D, et al. Non-excisional face and neck tightening using a novel subdermal radiofrequency thermo-coagulative device. J Cosmet Dermatol Sci Appl 2011;1:141-6.

13. Divaris M, Boisnic S, Branchet MC, et al. A clinical and histological study of radiofrequency-assisted liposuction (RFAL) mediated skin tightening and cellulite improvement: RFAL for skin tightening. J Cosmet Dermatol Sci Appl 2011;1:36-42.

14. Mulholland RS. Nonexcisional, minimally invasive rejuvenation of the neck. Clin Plast Surg 2014;41:11-31.

15. Alexiades-Armenakas M. Rhytides, laxity, and photoaging treated with a combination of radiofrequency, diode laser, and pulsed light and assessed with a comprehensive grading scale. J Drugs Dermatol 2006;5: 731-8.

16. Alexiades-Armenakas M. Nonablative skin tightening with a variable depth heating 1310-nm wavelength laser in combination with surface cooling. J Drugs Dermatol 2007;6:1096-103.

17. Alexiades-Armenakas M, Dover JS, Arndt KA. Unipolar versus bipolar radiofrequency treatment of rhytides and laxity using a mobile painless delivery method. Lasers Surg Med 2008;40:446-53.

18. Alexiades-Armenakas M. Assessment of the mobile delivery of infrared light (1100-1800 nm) for the treatment of facial and neck skin laxity. J Drugs Dermatol 2009;8:221-6. 